\begin{tabular}{|c|c|c|c|c|c|c|}
\hline 2016 & 36814886 & 100 & 115982 & 0,3 & 17904060 & 48,6 \\
\hline & \multicolumn{2}{|c|}{ Рыболовство, рыбоводство } & \multicolumn{2}{|c|}{$\begin{array}{c}\text { Добыча полезных } \\
\text { ископаемых }\end{array}$} & \multicolumn{2}{|c|}{ Обрабатывающие производства } \\
\hline & тыс. руб. & стр-ра, \% & тыс. руб. & стр-ра, $\%$ & тыс. руб. & стр-ра, \% \\
\hline 2012 & 19359 & 0,1 & 54102 & 0,4 & 6364867 & 45,6 \\
\hline \multirow[t]{3}{*}{2016} & 7250 & 0,02 & 4905700 & 13,3 & 27297061 & 74,1 \\
\hline & \multicolumn{2}{|c|}{$\begin{array}{c}\text { Производство и } \\
\text { распределение } \\
\text { электроэнергии, газа и воды }\end{array}$} & \multicolumn{2}{|c|}{ Строительство } & \multicolumn{2}{|c|}{$\begin{array}{c}\text { Оптовая и розничная торговля; } \\
\text { ремонт автотр. ср-в, мот., быт. } \\
\text { изд. и предм. личн. польз. }\end{array}$} \\
\hline & тыс. руб. & стр-ра, \% & тыс. руб. & стр-ра, $\%$ & тыс. руб. & стр-ра, \% \\
\hline 2012 & -7784131 & $-55,7$ & 432504 & 3,1 & 5245617 & 37,5 \\
\hline \multirow[t]{3}{*}{2016} & -28973728 & $-78,7$ & 1335426 & 3,6 & 7489905 & 20,3 \\
\hline & \multicolumn{2}{|c|}{ Гостиницы и рестораны } & \multicolumn{2}{|c|}{ Транспорт и связь } & \multicolumn{2}{|c|}{ Финансовая деятельность } \\
\hline & тыс. руб. & стр-ра, \% & тыс. руб. & стр-ра, \% & тыс. руб. & стр-ра, \% \\
\hline 2012 & 188798 & 1,4 & -175357 & $-1,3$ & -234655 & $-1,7$ \\
\hline \multirow[t]{3}{*}{2016} & 174478 & 0,5 & -338360 & $-0,9$ & 175611 & 0,5 \\
\hline & \multicolumn{2}{|c|}{$\begin{array}{c}\text { Операции с недвижимым } \\
\text { имуществом, аренда и } \\
\text { предоставление услуг } \\
\end{array}$} & \multicolumn{2}{|c|}{$\begin{array}{c}\text { Госуд. управл. и обесп. } \\
\text { военной безоп.; соц. страх. }\end{array}$} & \multicolumn{2}{|c|}{ Образование } \\
\hline & тыс. руб. & стр-ра, \% & тыс. руб. & стр-ра, \% & тыс. руб. & стр-ра, \% \\
\hline 2012 & 1000715 & 7,2 & 0 & 0 & 1275 & 0,01 \\
\hline \multirow[t]{3}{*}{2016} & 5441069 & 14,8 & 0 & 0 & 3901 & 0,01 \\
\hline & \multicolumn{2}{|c|}{$\begin{array}{c}\text { Здравоохранение и } \\
\text { предоставление социальных } \\
\text { услуг }\end{array}$} & \multicolumn{2}{|c|}{$\begin{array}{c}\text { Предоставление прочих } \\
\text { коммунальных, социальных и } \\
\text { персональных услуг }\end{array}$} & & \\
\hline & тыс. руб. & стр-ра, \% & тыс. руб. & стр-ра, \% & & \\
\hline 2012 & 237856 & 1,7 & 25976 & 0,2 & & \\
\hline 2016 & 1175239 & 3,2 & 101292 & 0,3 & & \\
\hline
\end{tabular}

Источник: расчет автора

1. Маркс, К. Капитал. Т.1 / К. Маркс. - М. : Издательство политической литературы, 1969.

2. Мануйленко, В. В. Развитие инноваций в системе финансового менеджмента коммерческих организаций: монография / В. В. Мануйленко, А. А. Мищенко. - М.: Перо, 2016. - 255 с.

3. Мануйленко, В. В. Совершенствование методики оценки достаточности собственных средств (капитала) коммерческого банка : монография / В. В. Мануйленко, А. В. Малеева. - Ставрополь : ГОУ ВПО «СевКавГТУ», 2006. - 209 с.

Локтионова М.А.

Оценка прибыльных и убыточных коммерческих корпоративных организаций с позиции формирования их финансового потенциала

Филиал ФГБОУ ВО «Московский технологический университет» в г. Ставрополе «Филиал МИРЭА»

doi 10.18411/scc-30-09-2017-04

(Россия, Ставрополь)

idsp 000001:scc-30-09-2017-04

Совокупность корпоративных финансовых систем объединенных единой целью - развития финансового состояния организаций способствует формированию финансового потенциала в регионе в целом, а эффективно привлекаемые ресурсы увеличивают его.

Величина финансового потенциала является параметром, позволяющим региону оценить возможности его финансовой деятельности [1].

Итак, чем эффективней используются ресурсы, тем выше финансовый потенциал региона, тем сильнее проявляется синергетический эффект.

В качестве объекта исследования выбран Ставропольский край, оценивающий развитие экономической деятельности организаций. 
Состав и структура доходов субъектов и входящих в него организаций, во многом определяются финансовым положением организаций расположенных на той или иной территории, и, в первую очередь массой создаваемых первичных доходов прибылью. Финансовые результаты деятельности организаций являются отражением состояния и использования финансового потенциала региона.

Основу структуры ООО региона составляют оптовая и розничная торговля в 2010 -2016гг. , 45,0\% - 41,1 \%, в общем объёме приходится высокий удельный вес и на обрабатывающие отрасли 2010 - 2016гг. 11,27\% - 10,2\%, строительство 10,4\% $12,4 \%$, транспорт и связь 4,2\% - 4,9\%, гостиницы и рестораны 4,5\% - 3,8\%, сельское хозяйство $2,9 \%$ - 3,2\%, операции с недвижимым имуществом аренда и предоставление услуг 16,2\% - 17,1\% (Таблица 1).

Таблица 1

Институциональное описание ООО региона по видам экономической деятельности (на примере Ставропольского края)

\begin{tabular}{|c|c|c|c|c|c|c|c|c|}
\hline \multirow[t]{2}{*}{ Годы } & \multicolumn{2}{|c|}{ Всего ОOO } & \multicolumn{2}{|c|}{$\begin{array}{c}\text { Сельское } \\
\text { хозяйство, охота } \\
\text { и лесное хозяйство }\end{array}$} & \multicolumn{2}{|c|}{$\begin{array}{c}\text { Добыча полезных } \\
\text { ископаемых }\end{array}$} & \multicolumn{2}{|c|}{$\begin{array}{c}\text { Обрабатывающие } \\
\text { производства }\end{array}$} \\
\hline & ед. & $\%$ & ед. & $\%$ & & ед. & $\%$ & ед. \\
\hline 2010 & 30366 & 100 & 845 & 2,9 & 108 & 0,3 & 3373 & 11,27 \\
\hline 2011 & 30429 & 100 & 840 & 2,7 & 109 & 0,3 & 3412 & 11,2 \\
\hline 2012 & 31086 & 100 & 944 & 3,0 & 108 & 0,3 & 3439 & 11,1 \\
\hline 2013 & 32214 & 100 & 984 & 3,0 & 111 & 0,3 & 3479 & 10,8 \\
\hline 2014 & 33319 & 100 & 1058 & 3,2 & 116 & 0,3 & 3538 & 10,6 \\
\hline 2015 & 34599 & 100 & 1085 & 3,1 & 130 & 0,4 & 3648 & 10,5 \\
\hline \multirow[t]{3}{*}{2016} & 34055 & 100 & 1092 & 3,2 & 126 & 0,4 & 3518 & 10,2 \\
\hline & \multicolumn{2}{|c|}{$\begin{array}{c}\text { Производство и } \\
\text { распределение } \\
\text { электроэнергии, газа и } \\
\text { воды } \\
\end{array}$} & \multicolumn{2}{|c|}{ Строительство } & \multicolumn{2}{|c|}{$\begin{array}{c}\text { Оптовая и } \\
\text { розничная } \\
\text { торговля; ремонт } \\
\text { автотр., бытовых } \\
\text { изделий и др. } \\
\end{array}$} & \multicolumn{2}{|c|}{$\begin{array}{c}\text { Гостиницы и } \\
\text { рестораны }\end{array}$} \\
\hline & ед. & $\%$ & ед. & $\%$ & ед. & $\%$ & ед. & $\%$ \\
\hline 2010 & 97 & 0,3 & 3157 & 10,4 & 13762 & 45,0 & 1357 & 4,5 \\
\hline 2011 & 106 & 0,3 & 3215 & 10,7 & 13436 & 44,3 & 1340 & 4,4 \\
\hline 2012 & 123 & 0,4 & 3463 & 11,1 & 13321 & 42,8 & 1353 & 4,3 \\
\hline 2013 & 125 & 0,4 & 3750 & 11,6 & 13573 & 42,1 & 1367 & 4,2 \\
\hline 2014 & 131 & 0,4 & 3996 & 12,0 & 13874 & 41,6 & 1393 & 4,2 \\
\hline 2015 & 132 & 0,4 & 4239 & 12,2 & 14332 & 41,4 & 1391 & 4,0 \\
\hline \multirow[t]{3}{*}{2016} & 137 & 0,4 & 4240 & 12,4 & 13998 & 41,1 & 1307 & 3,8 \\
\hline & \multicolumn{2}{|c|}{ Транспорт и связь } & \multicolumn{2}{|c|}{$\begin{array}{c}\text { Финансовая } \\
\text { деятельность }\end{array}$} & \multicolumn{2}{|c|}{$\begin{array}{c}\text { Операции с } \\
\text { недвижимым } \\
\text { имуществом, } \\
\text { аренда и } \\
\text { предоставление } \\
\text { услуг }\end{array}$} & \multicolumn{2}{|c|}{$\begin{array}{l}\text { Здравоохранение и } \\
\text { предоставление } \\
\text { социальных услуг }\end{array}$} \\
\hline & ед. & $\%$ & ед. & $\%$ & ед. & $\%$ & ед. & $\%$ \\
\hline 2010 & 1236 & 4,2 & 260 & 0,8 & 4917 & 16,2 & 478 & 1,6 \\
\hline 2011 & 1286 & 4,2 & 285 & 0,9 & 5083 & 16,7 & 526 & 1,7 \\
\hline 2012 & 1349 & 4,3 & 321 & 1,0 & 5258 & 16,9 & 610 & 1,9 \\
\hline 2013 & 1487 & 4,6 & 355 & 1,1 & 5452 & 16,9 & 693 & 2,1 \\
\hline 2014 & 1601 & 4,8 & 373 & 1,1 & 5639 & 16,9 & 759 & 2,3 \\
\hline 2015 & 1687 & 4,9 & 387 & 1,1 & 5871 & 16,9 & 829 & 2,4 \\
\hline 2016 & 1697 & 4,9 & 369 & 1,0 & 5828 & 17,1 & 892 & 2,6 \\
\hline
\end{tabular}

В акционерных обществах региона, значимая доля объема схожа по своему составу с обществом ограниченной ответственности, обрабатывающие отрасли занимают лидирующие позиции, оптовая и розничная торговля стоит на втором месте, необходимо отметить, что все значимые показатели ПАО и НАО на протяжении семи 
лет в отличии от ООО региона, снижались, что свидетельствуют о низкой экономической эффективности Ставропольского края, лишь сельское хозяйство в НАО региона осталось на прежнем уровне 2010-2016гг. 81\% - 81\% (Таблица 2) [2].

Таблииа 2

Институциональное описание АО региона по видам экономической деятельности (на примере Ставропольского края)

\begin{tabular}{|c|c|c|c|c|c|c|c|c|}
\hline \multirow[t]{2}{*}{ Годы } & \multicolumn{2}{|c|}{ Всего АO } & \multicolumn{2}{|c|}{$\begin{array}{c}\text { Сельское хозяйство, } \\
\text { охота } \\
\text { и лесное хозяйство }\end{array}$} & \multicolumn{2}{|c|}{$\begin{array}{c}\text { Добыча полезных } \\
\text { ископаемых }\end{array}$} & \multicolumn{2}{|c|}{$\begin{array}{c}\text { Обрабатывающие } \\
\text { производства }\end{array}$} \\
\hline & ед. & $\%$ & ед. & $\%$ & $\%$ & ед. & $\%$ & ед. \\
\hline 2010 & 1569 & 100 & 130 & 8,3 & 9 & 0,6 & 331 & 21,1 \\
\hline 2011 & 1449 & 100 & 124 & 8,5 & 9 & 0,6 & 304 & 21,0 \\
\hline 2012 & 1361 & 100 & 121 & 8,9 & 8 & 0,6 & 282 & 20,7 \\
\hline 2013 & 1288 & 100 & 122 & 9,4 & 9 & 0,7 & 260 & 20,2 \\
\hline 2014 & 1221 & 100 & 118 & 9,6 & 10 & 0,8 & 248 & 20,3 \\
\hline 2015 & 1134 & 100 & 116 & 10,2 & 6 & 0,5 & 229 & 20,3 \\
\hline \multirow[t]{3}{*}{2016} & 1010 & 100 & 105 & 10,4 & 6 & 0,6 & 205 & 20,3 \\
\hline & \multicolumn{2}{|c|}{$\begin{array}{c}\text { Производство и } \\
\text { распределение } \\
\text { электроэнергии, газа и } \\
\text { воды }\end{array}$} & \multicolumn{2}{|c|}{ Строительство } & \multicolumn{2}{|c|}{$\begin{array}{c}\text { Оптовая и } \\
\text { розничная торговля; } \\
\text { ремонт автотр., } \\
\text { бытовых изделий и } \\
\text { др. } \\
\end{array}$} & \multicolumn{2}{|c|}{$\begin{array}{c}\text { Гостиницы и } \\
\text { рестораны }\end{array}$} \\
\hline & ед. & $\%$ & ед. & $\%$ & ед. & $\%$ & ед. & $\%$ \\
\hline 2010 & 62 & 3,9 & 194 & 12,3 & 353 & 22,5 & 21 & 1,3 \\
\hline 2011 & 61 & 4,5 & 181 & 12,5 & 308 & 21,2 & 20 & 1,4 \\
\hline 2012 & 60 & 4,4 & 175 & 12,8 & 266 & 19,5 & 21 & 1,5 \\
\hline 2013 & 59 & 4,6 & 166 & 12,9 & 241 & 18,7 & 21 & 1,6 \\
\hline 2014 & 58 & 4,7 & 152 & 12,4 & 231 & 18,9 & 20 & 1,6 \\
\hline 2015 & 52 & 4,6 & 142 & 12,5 & 215 & 18,9 & 18 & 1,6 \\
\hline \multirow[t]{3}{*}{2016} & 57 & 5,6 & 125 & 12,4 & 178 & 17,6 & 18 & 1,8 \\
\hline & \multicolumn{2}{|c|}{ Транспорт и связь } & \multicolumn{2}{|c|}{$\begin{array}{c}\text { Финансовая } \\
\text { деятельность }\end{array}$} & \multicolumn{2}{|c|}{$\begin{array}{c}\text { Операции с } \\
\text { недвижимым } \\
\text { имуществом, аренда } \\
\text { и предоставление } \\
\text { услуг }\end{array}$} & \multicolumn{2}{|c|}{$\begin{array}{l}\text { Здравоохранение и } \\
\text { предоставление } \\
\text { социальных услуг }\end{array}$} \\
\hline & ед. & $\%$ & ед. & $\%$ & ед. & $\%$ & ед. & $\%$ \\
\hline 2010 & 123 & 7,8 & 33 & 2,1 & 272 & 17,3 & 18 & 1,1 \\
\hline 2011 & 119 & 8,2 & 31 & 2,1 & 252 & 17,4 & 17 & 1,2 \\
\hline 2012 & 115 & 8,4 & 23 & 1,7 & 252 & 18,5 & 7 & 0,5 \\
\hline 2013 & 108 & 8,4 & 20 & 1,5 & 247 & 19,2 & 13 & 1,0 \\
\hline 2014 & 106 & 8,9 & 19 & 1,5 & 227 & 18,6 & 13 & 1,1 \\
\hline 2015 & 100 & 8,8 & 17 & 1,5 & 208 & 18,4 & 13 & 1,1 \\
\hline 2016 & 91 & 9,0 & 15 & 1,5 & 182 & 18,0 & 13 & 1,3 \\
\hline
\end{tabular}

Удельный вес производственных кооперативов региона весьма незначителен, сельское хозяйство с 2010 года по 2016 год сократилось, 274-198, однако структура исследуемого показателя в 2016г. составила $80,8 \%$, что означает, остальные показатели в совокупности составляют лишь 19,2\% (Таблица 3 ).

Таблица 3

Институциональное описание производственных кооперативов по видам экономической деятельности (на примере Ставропольского края)

\begin{tabular}{|c|c|c|c|c|c|c|c|c|}
\hline \multirow[t]{2}{*}{ Годы } & \multicolumn{2}{|c|}{$\begin{array}{c}\text { Всего крестьянских } \\
\text { ферм. хозяйств }\end{array}$} & \multicolumn{2}{|c|}{$\begin{array}{c}\text { Сельское хозяйство, } \\
\text { охота } \\
\text { и лесное хозяйство }\end{array}$} & \multicolumn{2}{|c|}{$\begin{array}{c}\text { Добыча полезных } \\
\text { ископаемых }\end{array}$} & \multicolumn{2}{|c|}{$\begin{array}{c}\text { Обрабатывающие } \\
\text { производства }\end{array}$} \\
\hline & ед. & $\%$ & ед. & $\%$ & $\%$ & ед. & $\%$ & ед. \\
\hline 2010 & 358 & 100 & 274 & 76,5 & 0 & 0 & 21 & 5,9 \\
\hline 2011 & 321 & 100 & 249 & 77,6 & 0 & 0 & 17 & 5,3 \\
\hline 2012 & 301 & 100 & 244 & 81,1 & 0 & 0 & 17 & 5,7 \\
\hline
\end{tabular}




\begin{tabular}{|c|c|c|c|c|c|c|c|c|}
\hline 2013 & 292 & 100 & 238 & 81,5 , & 0 & 0 & 15 & 5,2 \\
\hline 2014 & 276 & 100 & 223 & 80,8 & 0 & 0 & 13 & 4,7 \\
\hline 2015 & 268 & 100 & 216 & 80,6 & 0 & 0 & 13 & 4,9 \\
\hline \multirow[t]{3}{*}{2016} & 245 & 100 & 198 & 80,8 & 0 & 0 & 11 & 4,5 \\
\hline & \multicolumn{2}{|c|}{$\begin{array}{c}\text { Производство и } \\
\text { распределение } \\
\text { электроэнергии, газа и } \\
\text { воды }\end{array}$} & \multicolumn{2}{|c|}{ Строительство } & \multicolumn{2}{|c|}{$\begin{array}{c}\text { Оптовая и } \\
\text { розничная торговля; } \\
\text { ремонт автотр., } \\
\text { бытовых изделий и } \\
\text { др. } \\
\end{array}$} & \multicolumn{2}{|c|}{$\begin{array}{c}\text { Гостиницы и } \\
\text { рестораны }\end{array}$} \\
\hline & ед. & $\%$ & ед. & $\%$ & ед. & $\%$ & ед. & $\%$ \\
\hline 2010 & 1 & 0,3 & 15 & 4,2 & 20 & 5,6 & 1 & 0,3 \\
\hline 2011 & 1 & 0,3 & 13 & 4,0 & 16 & 5,0 & 1 & 0,3 \\
\hline 2012 & 1 & 0,3 & 12 & 4,0 & 9 & 3,0 & 0 & 0 \\
\hline 2013 & 1 & 0,3 & 12 & 4,1 & 9 & 3,1 & 0 & 0 \\
\hline 2014 & 1 & 0,4 & 12 & 4,3 & 8 & 2,9 & 0 & 0 \\
\hline 2015 & 1 & 0,4 & 12 & 4,5 & 8 & 2,9 & 0 & 0 \\
\hline \multirow[t]{3}{*}{2016} & 1 & 0,4 & 12 & 4,9 & 7 & 3,0 & 0 & 0 \\
\hline & \multicolumn{2}{|c|}{ Транспорт и связь } & \multicolumn{2}{|c|}{$\begin{array}{c}\text { Финансовая } \\
\text { деятельность }\end{array}$} & \multicolumn{2}{|c|}{$\begin{array}{c}\text { Операции с } \\
\text { недвижимым } \\
\text { имуществом, аренда } \\
\text { и предоставление } \\
\text { услуг }\end{array}$} & \multicolumn{2}{|c|}{$\begin{array}{c}\text { Здравоохранение и } \\
\text { предоставление } \\
\text { социальных услуг }\end{array}$} \\
\hline & ед. & $\%$ & ед. & $\%$ & ед. & $\%$ & ед. & $\%$ \\
\hline 2010 & 4 & 1,1 & 0 & 0 & 10 & 2,8 & 1 & 0,3 \\
\hline 2011 & 4 & 1,2 & 0 & 0 & 8 & 2,6 & 1 & 0,3 \\
\hline 2012 & 3 & 1,0 & 0 & 0 & 5 & 1,7 & 1 & 0,3 \\
\hline 2013 & 2 & 0,8 & 0 & 0 & 5 & 1,7 & 1 & 0,3 \\
\hline 2014 & 2 & 0,7 & 0 & 0 & 7 & 2,5 & 1 & 0,4 \\
\hline 2015 & 2 & 0,7 & 0 & 0 & 6 & 2,2 & 1 & 0,4 \\
\hline 2016 & 2 & 0,8 & 0 & 0 & 5 & 2,0 & 1 & 0,4 \\
\hline
\end{tabular}

В целом финансовое положение корпоративных организаций Ставропольского края в 2010-2016гг. характеризуется повышением числа рентабельности производства, сокращением числа убыточных организаций сельского хозяйства $4,4-2,1 \%$, увеличением числа финансовых ресурсов для стабильной деятельности хозяйствующих субъектов [3].

Несомненным лидером из всех представленных организаций является общество с ограниченной ответственностью. Представим на рисунке 1 динамику финансового потенциала ООО со значимыми показателями.

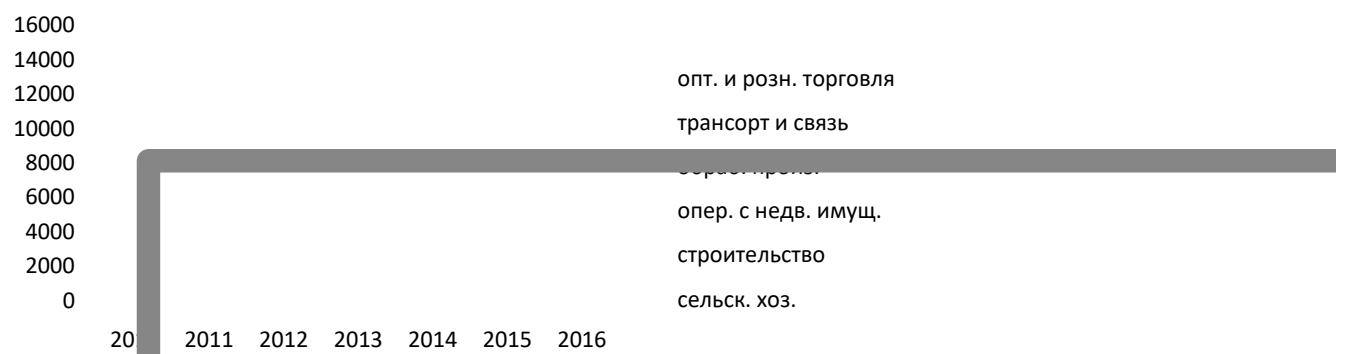

Рисунок 1 - Оценка финансового потенциила развивающихся отраслей ООО

Доминирующее положение всех хозяйствующих субъектов исследуемого региона свидетельствует о эффективном использовании финансовых ресурсов, изучении финансовых стратегий вероятных конкурентов, их экономических, 
финансовых возможностей, разработке и осуществлению мероприятий по обеспечению финансовой устойчивости.

Эффективное использование финансового потенциала напрямую зависит от эффективности исполнения регионального бюджета, который предназначен для финансового обеспечения задач и функций региона[4].

$* * *$

1. Баранов В.В. Финансовый менеджмент. Механизмы финансового управления предприятием в традиционных и наукоемких отраслях. Учеб. пособие / В.В. Баранов. - М.: Дело, 2012. - 387 с.

2. Гиляровская, Л. Т. Анализ и оценка финансовой устойчивости коммерческой организации: учебное пособие для студентов вузов / Л. Т. Гиляровская, А. В. Ендовицкая. - М.: ЮНИТИ-ДАНА, 2012. $159 \mathrm{c.}$

3. Локтионова М.А./ Характеристика общих и специальных методов оценки финансового потенциала организации: достоинства и недостатки/ По результатам ХX Международной научно-практической конференции «Экономика и юриспруденция: теория и практика», Санкт-Петербург, 19 мая 2017 г.

4. Управление прибылью в акционерных обществах региона: теория и практика /Мануйленко В.В., Садовская Т.А.// Москва, 2014. Том Книга 1

\section{Andreeva T.A. \\ The Application of Mechanisms of Public-private Partnership in the Arctic Zone of Russian Federation}

Saint-Petersburg State Marine Technical University (Russia, Saint-Petersburg)

doi 10.18411/scc-30-09-2017-05

idsp 000001:scc-30-09-2017-05

The Arctic is a unique geopolitical region that contacts with America, Europe, Asia, the Atlantic and Pacific Ocean, a region with a large territory, with the lowest population density on Earth and large strategic reserves of minerals.

The region concentrates in itself most of the unique and large hydrocarbon fields discovered in Russia. The Russian shelf plays a key role in maintaining world oil production. This is an important reserve for the growth of mineral and raw materials base of hydrocarbons for long-term perspective. The production of hydrocarbons here will play an important role in the energy balance of Russia, being necessary to replace the decline in production in existing fields and maintain the country's condition of growing domestic and external demand for oil and gas.

For the qualitative development of the hydrocarbon potential, it is necessary to form production centers located in the areas where the largest oil and gas fields are located, with the creation of the necessary infrastructure ensuring uninterrupted extraction, processing and transportation of raw materials and products of processing.

Among the main directions of economic activities in the Arctic, one can single out the extraction of hydrocarbons and the development of the Northern Sea Route (NSR). The bulk of hydrocarbon fields discovered on the Arctic shelf has extremely high development costs and requires the creation of unique technologies on a global scale which carries significant environmental risks. The internal development of the region should become the basis for creating the logistics potential of the NSR. It is necessary to turn the NSR into a full-fledged transport artery, through which cargo ships will go round the year and regularly. Revitalization of activities in these areas will provide demand for marine equipment capable of operating in extreme climatic and ice conditions. Navigation, hydro meteorological, telecommunication, rescue and repair technologies and will ensure the development of port infrastructure.

To realize the existing resource potential, social and economic development of remote Arctic regions, it is necessary to use the mechanism of public-private partnership in which the 